\title{
O ESTATUTO DA IMAGEM-PULSÃO EM \\ Cronicamente INVIÁVEl E AMARElo Manga
}

http://dx.doi.org/10.1590/1984-0292/1315

\section{Alexandre Rocha da Silva, Bruno Bueno Pinto Leites $\star$, Guilherme Gonçalves da Luz}

Universidade Federal do Rio Grande do Sul, Porto Alegre, RS, Brasil

\section{RESUMo}

Este artigo retoma o debate inaugurado por Gilles Deleuze sobre a imagempulsão e avalia como tais imagens se fazem presentes no cinema brasileiro contemporâneo. O trabalho recua até Sigmund Freud para explicitar o conceito de pulsão e até Herbert Marcuse para pensar o engajamento das pulsões nas relações socioculturais. Neste percurso, descreve-se uma nova forma de pensamento no cinema a partir do conceito. No contexto do cinema brasileiro, identificou-se que não há um filme constituído unicamente por imagens-pulsão, em lugar disso, elas se encontram dispersas em cenas de diferentes filmes, desempenhando funções diversas nas relações entre mundos originários e derivados.

Palavras-chave: imagem-pulsão; cinema; Gilles Deleuze; cinema brasileiro.

\section{The CONSTITUTION OF THE IMPULSE-IMAGE IN Chronically Unfeasible and Mango Yellow}

\begin{abstract}
This paper aims to continue the debate began by Gilles Deleuze about the impulseimage and evaluate in which ways these images exist in contemporary Brazilian cinema. In order to describe how the impulse-images produce a new thought in Cinema, it's retrieved the psychoanalytic concept of Drive in Sigmund Freud's theory and its use by Herbert Marcuse in Sociology. In this work, it 's concluded that the impulse-image in contemporary cinema does not characterize films in its strict sense, but it's found dispersed in scenes from different films, also having an important role in the relationships between originary worlds and derived milieux.
\end{abstract}

Keywords: impulse-image; cinema; Gilles Deleuze; Brazilian cinema.

\footnotetext{
$\star$ Trabalho realizado com apoio do CNPq e da CAPES.

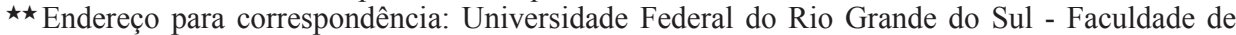
Biblioteconomia e Comunicação - Programa de Pós-Graduação em Comunicação e Informação. R. Ramiro Barcelos, 2705 - $2^{\circ}$.andar - Santana. CEP: 90.035-007 - Porto Alegre - RS - Brasil. E-mail: arsrocha@gmail.com, bleites2003@hotmail.com,guilh.gl@gmail.com
} 


\section{INTRODUÇão}

Uma das características decisivas nos trabalhos de Gilles Deleuze (1985, 2007) sobre cinema é a sua abordagem teórico-metodológica construída a partir de conceitos de Henri Bergson e Charles S. Peirce. O próprio Bergson (2005) havia utilizado o cinema como uma ferramenta ilustrativa secundária para exemplificar a perspectiva que condenava, aquela que só via o tempo espacializado. Deleuze, porém, para além da análise do aparato técnico do cinema, aproveita a rede conceitual bergsoniana que se articula ao redor do conceito de imagem. Para Bergson, a matéria é uma imagem-matéria-movimento. O cinema, que nasceu no mesmo ano de publicação de Matéria e Memória (BERGSON, 2006), mostra-nos o mesmo: as imagens cinematográficas existem como atualização de um fluxo que lhes é anterior de direito. Assim, o cinema é uma máquina que atualiza imagens gerando signos cujo funcionamento expressa o que havia de novo no pensamento.

Na perspectiva de Bergson não há mais a ideia de uma imagem inscrita na consciência, pois a própria consciência é uma imagem. Tudo o que existe se torna imagem, como um emaranhado de movimentos que se interconectam simultaneamente em uma matéria-fluxo sem centro de determinação, pois há um plano de imanência que constitui a matéria e compreende este conjunto infinito de imagens entendidas como movimentos. Com base em tal determinação, Deleuze (2009, p. 97) afirma que "a imagem-movimento e a matéria-fluxo são estritamente a mesma coisa". Entre os fluxos de matéria existem conjuntos finitos, cortes imóveis, mas o plano de imanência é o movimento que se dá entre os conjuntos ou de um conjunto para o outro, por isso é um "corte móvel". Este plano de imanência é chamado por Deleuze (2009, p. 98) de "agenciamento maquínico das imagens-movimento".

Como expressões de um modo singular de pensar, as imagens de cinema ao longo do século XX passaram a ter cada vez mais relevância, produzindo imagens que habitam e reconfiguram as materialidades do mundo.

Com tal perspectiva, compreendemos em que medida as imagens de cinema engajam-se também nos processos de subjetivação. Os processos de subjetivação são produzidos no confronto de imagens, de modo que as imagens de cinema pensam e agem sobre esses processos. Conforme a perspectiva de Denílson Lopes (2014), pesquisar o cinema implica pesquisar novos afetos no mundo. Neste artigo, analisamos um processo específico no cinema brasileiro contemporâneo, qual seja, a imagem-pulsão. Primeiramente, partimos do conceito de imagem-pulsão em Deleuze. Com o objetivo de embasar epistemologicamente o percurso teórico, utilizamos a teoria das pulsões de Sigmund Freud. Após, analisamos dois filmes brasileiros contemporâneos e, finalmente, ensaiamos algumas problematizações contextuais desse universo das imagens-pulsão no Brasil.

O conceito de imagem-pulsão foi proposto por Deleuze (1985, p. 157-199) em Cinema I: a imagem-movimento para compreender, sobretudo os filmes de Luis Buñuel e Erich von Stroheim. Trata-se de um tipo de imagem-movimento muito pouco explorada pelos estudos deleuzeanos em cinema, se comparados com os estudos feitos acerca das imagens afecção, ação e relação. ${ }^{1}$ Situada entre a 
imagem-afecção e a imagem-ação, a imagem-pulsão designa um tipo de sensibilidade no mundo que, na filosofia do cinema de Deleuze, opera uma ponte com o universo conceitual de Cinema 2: a imagem-tempo (2007). Em última análise, as imagens-pulsão não chegam a ser temporais devido à fixação pela negatividade do tempo, que se expressa na recorrência do pútrido, do abjeto, do animalesco.

Nos livros de cinema, Deleuze pouco explora o conceito de imagem-pulsão. Assim, neste artigo, procuramos refazer o percurso deleuzeano que o levou à elaboração da ideia de imagem-pulsão, partindo do conceito de pulsão em Sigmund Freud, com o auxílio das referências feitas pelo próprio Deleuze em outros de seus trabalhos, como Diferença e Repetição (DELEUZE, 2006) e Los signos del movimento y el tiempo (DELEUZE, 2011) e na apropriação do conceito de Freud feita por Marcuse (1975), em Eros e Civilização.

Após realizar a construção teórico-metodológica, analisamos dois filmes que, em algumas passagens, exploram a imagem-pulsão no cinema brasileiro contemporâneo: Cronicamente Inviável, de Sérgio Bianchi, e Amarelo Manga, de Cláudio Assis. Tais filmes não poderiam ser classificados como filmes de imagem-pulsão em senso estrito, porém exploram tais imagens, o que nos leva a considerar que a problemática da imagem-pulsão contemporaneamente pode ser investigada não em filmes específicos, mas a partir de cenas dispersas entre diferentes filmes.

\section{Das PUlsões Às imagens-PUlsão}

A concepção de Freud a respeito dos mecanismos pulsionais se apresenta ao mesmo tempo como crítica e como defesa do processo civilizatório. Para o autor, a história do homem é a história de sua repressão. Segundo Marcuse (1975), a cultura, ideia intimamente ligada à constituição do sujeito, atua coagindo na existência social e biológica do homem, reprimindo tanto seu comportamento perante os demais indivíduos quanto seus próprios impulsos pulsionais.

Para pesquisar o conceito de pulsão na teoria de Freud foi preciso rever sua obra, avaliar idas e vindas, reformulações, deslocamentos operados pelo autor ao longo de sua carreira. Freud organiza os sistemas pulsionais cercando-os, ora aproximando-os dos estímulos, criando relações com sistemas biológicos, ora articulando os princípios de prazer e realidade. $\mathrm{O}$ autor apresenta também os destinos das pulsões (suas formas de satisfação ou recalque), de seus componentes e de suas formas de ocorrência. Tal estratégia é vista, por este trabalho, como uma tentativa de construção de um conceito complexo e fugidio. A pulsão é um elemento que atua no limiar da consciência, portanto, pode ser vista como uma abstração que, para ser entendida, precisa se colocar no entremeio, em movimento.

$\mathrm{O}$ "princípio de realidade" é o elemento da pulsão que diz respeito ao contato do indivíduo com as forças repressoras constituídas pela cultura (FREUD, 2009). Ocorre quando os "impulsos animais convertem-se em instintos ${ }^{2}$ humanos sob a influência da realidade externa" (MARCUSE, 1975, p. 33). É dos estímulos psíquicos que deriva grande parte da psicanálise freudiana. Conceitos como sublimação, identificação, projeção, repressão e introjeção são caminhos pulsionais 
que atuam na mutabilidade dos sujeitos, mas suas formas de ocorrência só são materializadas através de um mundo sócio-histórico, que posteriormente Deleuze (1985) chamará de "meio derivado".

A ocorrência dessa transmutação nos processos pulsionais percorre um caminho que foi chamado por Freud de transformação do princípio de prazer em princípio de realidade (FREUD, 1975). Estas transformações obedecem a um traçado que vai sempre da pulsão ao meio sócio-histórico, por exemplo, da satisfação imediata à satisfação adiada, do prazer à restrição do prazer, da receptividade à produtividade. Tal mecanismo propõe a distinção entre processos mentais conscientes e inconscientes e entre a dimensão histórico-genética, construída a partir de suas camadas evolutivas, e a estrutural, regida pelo pensamento estruturado em linguagem. O princípio de realidade, deste modo, não chega a negar o princípio de prazer, uma vez que ele atua no prolongamento da satisfação. Esta estrutura pode ser associada, conforme veremos, ao que propôs Deleuze sobre a imagem-pulsão e sua função de atualização do mundo originário no meio derivado. Por ora, buscaremos uma breve sistematização da pulsão conforme pensou Freud e algumas de suas ramificações para além da psicanálise.

A pulsão consiste em um sistema econômico de energia, vital ou destrutiva, que atua com a finalidade de direcionar comportamentos através de uma dada estrutura de estímulos psíquicos, e é formada por um impulso inicial, uma meta, um objeto e uma satisfação (FREUD, 2013). Ela pode ser vista como um mecanismo que tensiona os princípios de prazer e realidade mantendo uma "eterna luta primordial pela existência" (MARCUSE, 1975, p. 37). Todas as formas pulsionais estão alicerçadas sobre a existência de dois elementos antagônicos e complementares - Eros e Tânatos - o primeiro referindo-se às pulsões de vida e, o segundo, às pulsões de morte. A sexualidade tenderá a confundir-se com Eros sempre que houver condições não repressivas à sua existência, e lutará por eternizar-se numa ordem permanente. Há uma relação de indissociabilidade entre Eros e Tânatos, conforme expõe Marcuse (1975, p. 199), "o fato brutal da morte nega redondamente a realidade de uma existência não repressiva, pois a morte é a negatividade do tempo".

Tal relação também foi estabelecida por Deleuze (2006, p. 26), ao afirmar que "Eros deve ser repetido, só pode ser vivido na repetição; mas Tânatos (como princípio transcendental) é o que dá a repetição a Eros, o que submete Eros à repetição". A vontade de eternizar-se transforma Eros em uma pulsão atemporal, não espacializada, mas sempre recalcada por Tânatos, pela temporalidade que a pulsão destrutiva imprime sobre o princípio de prazer.

Ao longo da construção teórica de Freud no campo da psicanálise, a pulsão se apresentou sob o domínio de três perspectivas: primeiramente, como conceito-limite entre o psíquico e o somático, posteriormente, como representante psíquico dos estímulos corporais e finalmente como medida de exigência de trabalho imposta ao psíquico (STRACHEY, 1974). 
Marcuse (1975), em Eros e Civilização, para além de uma análise acurada do conceito de pulsão em Freud, também o utiliza para a observação de fenômenos sociais. $\mathrm{O}$ autor, assim, propõe sistemas de tensionamentos sociais a partir de relações libidinais em conflito com os regimes de opressão das máquinas de controle (estado, igreja, instituições). Segundo o autor, "a energia do corpo humano revolta-se contra a repressão intolerável e lança-se contra as máquinas da repressão" (MARCUSE, 1975, p. 18). Esta perspectiva descentraliza a pulsão do sujeito e a torna um conceito capaz de manter contato com outros campos do conhecimento, como a sociologia, a história, a arte, a comunicação e o cinema. Os conflitos, para Marcuse, se encontram sempre intermediados pelas forças pulsionais, que tentam a todo tempo realizar o princípio de prazer no combate ao princípio de realidade.

Sobre a incidência das pulsões coletivas, Marcuse apresenta que, sempre que um dado nível de vida for insuficiente para harmonizar as relações de coexistência entre todos os tensionadores sociais, sejam pessoas e governantes, patrões e empregados, ricos e pobres, haverá uma espécie de engenharia social que fornecerá uma necessária catexia libidinal.

A partir de tais proposições, é possível compreender o conceito de imagem-pulsão. Em Deleuze (1985, p. 157-177), há um desdobramento do conceito freudiano de pulsão que determina a atuação de tal conceito nas imagens cinematográficas, as chamadas imagens-pulsão. Este pode ser visto como elemento central da presente investigação e, assim como em Freud, também é composto por quatro elementos: meio derivado, mundo originário, pulsões e comportamentos, organizados em pares de virtualidade e atualização: meio derivado/mundo originário e pulsões/comportamentos.

Deleuze atribui aos naturalistas as primeiras manifestações pulsionais nos meios artísticos. Segundo o autor (DELEUZE, 1985, p. 158), o escritor francês Émile Zola é a principal referência na aproximação dos mundos originários com os meios reais. Zola foi responsável pela criação de uma literatura que se baseava no real para a construção de um comportamento humano mitificado, pois acentuava seus traços de violência e bestialidade a fim de extrair-lhes o animalesco, o pulsional. Este movimento é o que Deleuze chama de arrancar pedaços, pois articula pulsões extraídas de comportamentos reais com partes de objetos situados em mundos originários.

O mundo originário implica uma relação de determinância com o meio derivado que lhe é correlato. Há claramente uma hierarquia nesta imagem: o mundo originário é o fundamental. De fato, esta importância do mundo originário pode ser a grande revelação, que se descortina por trás do pacato, do estável, do real e do normal.

Assim, no cinema, há vários elementos característicos da imagem-pulsão: personagens animalescos, carnes podres, lugares inóspitos e todo o tipo daquilo que é socialmente tido por perversão. Todavia, não podemos deduzir que está configurada uma imagem-pulsão pela simples presença de tais elementos, é preciso ainda a presença indispensável do mundo originário. É preciso ainda ressaltar, nessa pers- 
pectiva, que não devemos falar em mundos originários que sejam determinantes dos meios derivados e de mundos originários que não o sejam. O conceito de mundo originário já implica que exista um meio derivado correlato e dependente.

$\mathrm{O}$ que ocorre, portanto, com a presença das personagens animalescas na imagem-pulsão é que elas fazem o ponto de encontro entre as duas esferas. Tais personagens podem ser a própria encarnação do mundo originário, ou, ainda, o que finalmente se revela por trás das aparências no meio derivado.

Há inúmeras formas de trabalhar a dinâmica entre mundos originários e meios derivados. Isso favorece a riqueza e a beleza dessas imagens audiovisuais. Deleuze enumera dois grandes estilos: a relação por entropia, como nos casos recém-referidos, e a relação por repetição. $\mathrm{Na}$ entrópica ocorre a deterioração, enquanto na outra há uma espécie de condenação ao cíclico. Em ambos os casos, não há saída. O tempo, doente, faz-se implacável.

A condenação ao cíclico e à entropia são características presentes nos filmes Cronicamente Inviável, de Sérgio Bianchi, e Amarelo Manga, de Cláudio Assis, que passaremos a analisar como experiências estéticas da imagem-pulsão no cinema brasileiro.

\section{CRONICAMENTE INVIÁVEL E A IMAGEM-PULSÃO REPETITIVA}

A violência em Cronicamente Inviável (2000) reporta sempre à existência de um mundo originário, que conforma uma temporalidade composta para determinar que tudo é inviável. Daí que a violência reporta sempre ao mesmo lugar, a um tempo negativo e implacável.

Serão observadas três cenas sucessivas no filme, que configuram a sequência da "mulher carioca de classe média". É o ponto em que o filme se aproxima da história dessa mulher, que até então havia sido apenas tangenciada narrativamente. Na primeira e na terceira cenas tem-se a síntese de um conflito inerente à imagem-pulsão, obtido entre o mundo originário cronicamente inviável e os mundos derivados, seja do cinismo ou do sarcasmo. Na segunda cena encontra-se especialmente o pertencimento da imagem-pulsão à lógica da imagem-movimento $\mathrm{O}$ cinismo e o sarcasmo, nesses casos, constituem formas de expressão da imagem-pulsão inscritas no interior da imagem-movimento.

$\mathrm{Na}$ primeira cena, a mulher surpreende a doméstica em seu quarto com um namorado desconhecido. Imediatamente, começa a gritar com a empregada, descarregando uma fúria represada. Simultaneamente, o namorado da empregada também libera seus impulsos violentamente. Um concerto de impulsos reprimidos ganha a cena. Nessa situação-limite, são evidenciados elementos que estavam, até então, recalcados no discurso conduzido pela mulher de classe média, que reiterava o cinismo em relação à empregada, fingindo ser sua amiga e a fazendo sentir-se parte da família. Nessa mesma situação, a empregada desabafa revelando o quanto se sente humilhada ao longo dos anos. 
A planificação da cena, que corresponde aos planos utilizados para a sua consecução (BURCH, 1973, p. 11), confere destaque a esse momento pulsional, ao enquadrar a empregada sozinha no plano (quarto frame). Trata-se de uma ruptura, porque apenas a dona da casa aparecia sozinha no quadro até o momento (primeiro frame). É como se a revolta da trabalhadora doméstica conferisse-lhe o poder da exclusividade no quadro. Em seguida, a dona da casa, novamente sozinha no quadro, após dividi-lo com o homem (terceiro frame), choca-se com a revolta. Por fim, o grupo é reunido no mesmo enquadramento, que resolve a cena. Assim, percebe-se que a imagem-pulsão em Cronicamente Inviável é muito mais sugerida estética e narrativamente que plenamente realizada.

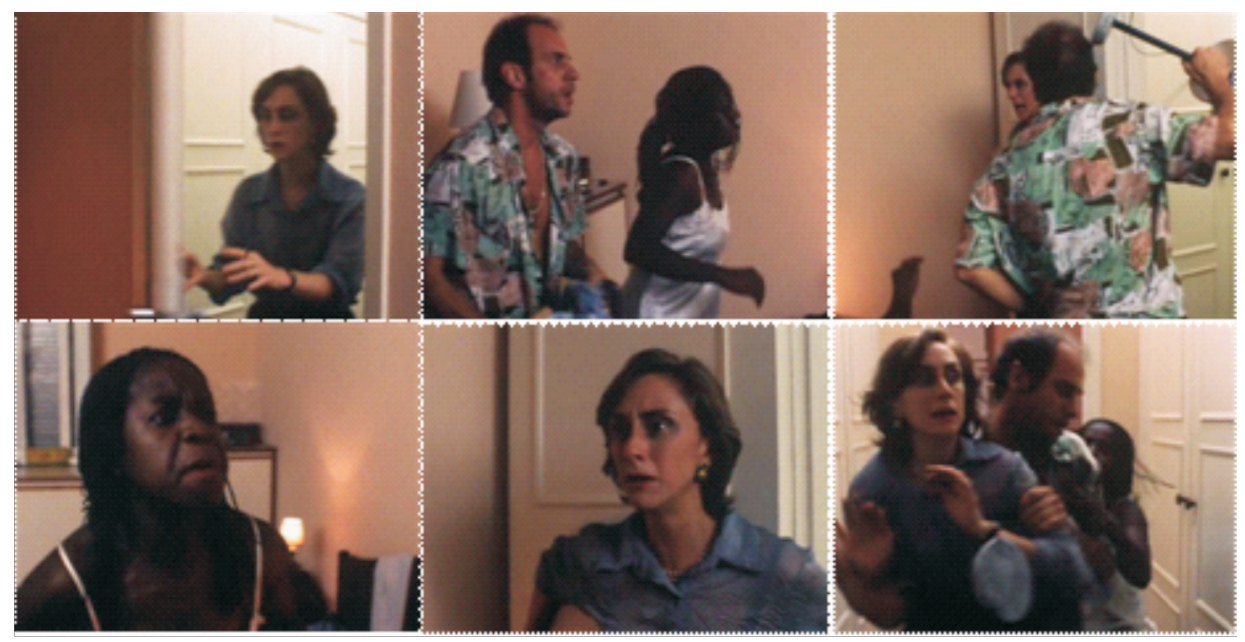

Figura 1 - Violência como manifestação do inviável

Fonte: (CRONICAMENTE..., 2000)

Na segunda cena, durante a ação que envolve o assalto, a captura do assaltante e a briga entre o filho e a mãe (frames 2 a 5 abaixo), a câmera permanece distanciada, sempre em plano conjunto. Aqui, a ideia de uma imagem-pulsão tende mais à ação que à afecção. O movimento da câmera é mínimo e ocorre apenas para manter a ação no centro do quadro. A câmera observa a ação de longe, sem dramatizá-la sob o efeito dos planos aproximados, de movimentos agressivos que recortem a ação, ou que denotem sua própria autonomia. Em suma, é uma postura observacional da câmera e da planificação da cena. É como se estivessemos assistindo à cena de um ângulo relativamente privilegiado, mas não mais privilegiado do que as demais personagens que habitam a praia. A estratégia de câmera e de planificação da cena não desenham o espaço e a ação dramática, sobretudo observam-lhes. Isso é o que Deleuze (2007, p. 155) conceitua como descrição orgânica, em que o objeto é tido como independente da câmera que o observa: "O que conta é que, cenários ou exteriores, o meio descrito seja posto como independente da descrição que a câmera dele faz, e valha por uma realidade supostamente independente". A descrição orgânica é aquilo que define a imagem-movimento propriamente dita. Consideramos relevante apresentar tais aspectos porque eles, 
de maneira muito clara, demonstram o pertencimento da imagem-pulsão ao universo das imagens-movimento, ainda que Deleuze reconheça nelas - as imagens-pulsão - o caráter de passagem da imagem-movimento à imagem-tempo, por um aspecto, e da afeção à ação, por outro. Logo, reiteramos, é o caráter transitivo de tais imagens que parece ser a reflexão mais relevante de Cronicamente Inviável para pensar a imagem-pulsão...

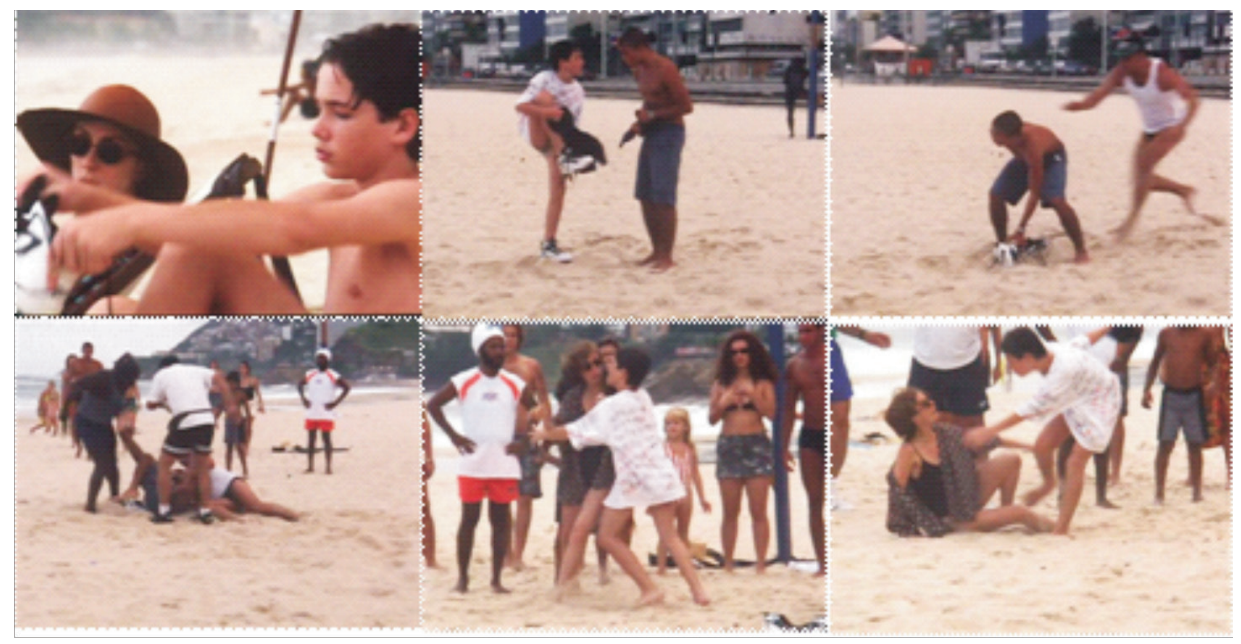

Figura 2 - Descrição orgânica

(Fonte: CRONICAMENTE..., 2000)

Vejamos o caso da terceira cena da sequência selecionada. Primeiro, (a) a "mulher carioca de classe média" conversa carinhosamente com as crianças de rua, depois (b) doa brinquedos a duas delas, e, em seguida (c) assiste passivamente à briga gerada pela disputa dos brinquedos e reflete, em voz over, sobre a situação das crianças de rua brasileiras. As duas primeiras partes da cena, até a doaçãodos brinquedos às crianças, compõem um entendimento que é subvertido pela terceira parte, sarcasticamente. Em princípio afeita às crianças, a personagem não se importa com a briga que o brinquedo gera. Pelo contrário, a câmera a enquadra detidamente em primeiro plano e é possível perceber uma expressão de satisfação com o acontecimento. Aqui há uma quebra de espectativa na cena, radicalizada pelo teor da reflexão: "[...] o Estado tem que ter o seu papel. Ele tem que dar é crack pras crianças de rua. Já que elas vão morrer mesmo, de frio, de umidade, de coceira, que seja com felicidade" (CRONICAMENTE..., 2000). Essa reflexão sarcástica confronta a primeira parte da cena, em que a personagem carinhosamente conversa com as crianças e doa os brinquedos, e além disso, afronta toda a construção discursiva prévia dessa personagem. Os jogos pulsionais aqui são sintetizados pela figura do sarcástico. Se as outras cenas dessa sequência já faziam isso, esta, agora, leva ao extremo. É esta a composição do inviável no filme: há sempre um fundo nefasto revelado. 

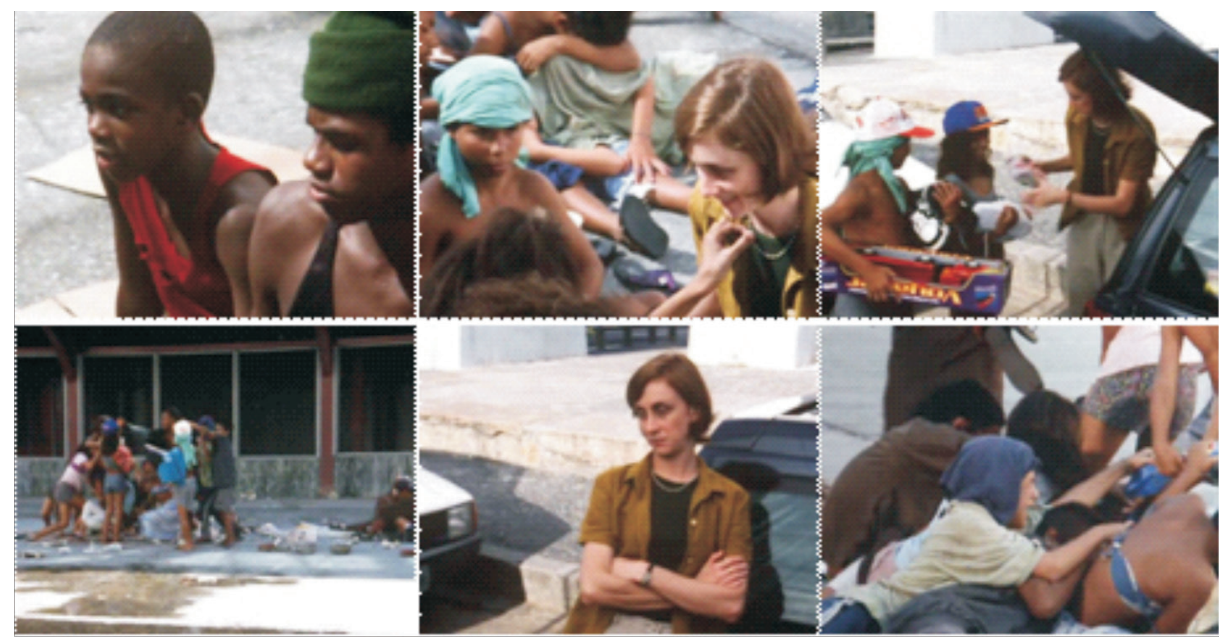

Figura 3 - Exemplo de manifestação do mundo originário

Fonte: (CRONICAMENTE..., 2000)

Os mundos originários das imagens-pulsão repetitivas conduzem sempre o meio derivado a uma repetição infinita, a uma repetição sem diferença, conforme vimos na teoria de Deleuze. Assim, essas imagens não necessariamente possuem a paixão pelo animalesco, pelo pútrido, como as imagens-pulsão entrópicas. $\mathrm{O}$ mundo originário no caso das imagens-pulsão por repetição é a força que conduz os meios derivados à repetição infinita sem diferença. Trata-se, evidentemente, no filme em análise, do que é crônico e inviável. Todavia, ocorre de a materialidade desses mundos originários por repetição ser mais dificilmente observada e analisada. O que é crônico e inviável no filme é algo que faz as situações, tidas com meios derivados, resolverem-se sempre no mesmo sentido, como a manifestação de uma doença crônica.

A pulsão em Cronicamente Inviável é antes uma operação que uma imagem propriamente dita. O filme expressa como pulsão a passagem de um mundo originário cronicamente inviável a um meio derivado ressentido, cínico e sarcástico. A imagem-pulsão, situada entre a afecção e a ação, parece ter duas faces. A primeira, voltada para os mundos originários, expressa o sentido do cronicamente inviável como princípio de realidade; a segunda, voltada ora para a afecção ora para a ação das personagens, expressa esteticamente as formas da pulsão na imagem que não constrói outra coisa que a imagem das pulsões em jogo.

\section{Amarelo Manga E A imageM-PUlsão entrópica}

A caracterização do mundo originário em Amarelo Manga ocorre pela delimitação do conceito de amarelo. É preciso atentar que as imagens-pulsão atualizam uma tendência naturalista no cinema, porque concebem uma pulsação que parte de um mundo primeiro e dominante com relação ao mundo atualizado dos meios derivados. Essa questão fica particularmente evidente em Amarelo Manga, que concentra 
sua força e sua violência nas tensões existentes nos processos que vão dos mundos originários aos meios derivados. No filme, o mundo originário é tido pelo "amarelo" enquanto o meio derivado organiza-se em espaços claramente degradados.

Podemos selecionar três grandes elementos de constituição da imagem-pulsão em Amarelo Manga, os quais repercutem entre si no decorrer da narrativa. O primeiro é preliminar: o próprio título. Sua caracterização é feita de elementos implícitos até aproximadamente a metade do filme, quando o conceito de "amarelo" é apresentado explicitamente, através de uma personagem secundária que o lê em um livro de Renato Carneiro Campos (1980, p. 67): “[...] Amarelo das doenças, das remelas dos olhos dos meninos, das feridas purulentas, dos escarros, das verminoses, das hepatites, das diarréias, dos dentes apodrecidos. O tempo interior amarelo, velho, desbotado, doente".

A proximidade com o dito por Deleuze acerca da imagem-pulsão é notória e impressiona inclusive pela referência à negatividade da concepção de tempo. Portanto, nesse ponto do filme, esclarece-se o conceito de amarelo, que reverbera o seu título. Já no final, na última cena, a personagem recém-liberta da moral religiosa joga fora a aliança e vai ao cabeleireiro, onde pede decididamente que o cabelo seja pintado de amarelo manga. Esses são três excertos que indicam a concepção do mundo originário no filme, mas são apenas as indicações mais explícitas. Entre elas, há todo um projeto que reforça essa concepção naturalista com referência a várias instâncias, como ao sexo, à religião e à violência.

É preciso considerar que Amarelo Manga é um filme-mosaico, sem uma personagem principal, mas com um grupo de personagens que têm semelhante importância em termos de protagonismo. Podemos verificar que em Amarelo Manga o principal não está nos conflitos internos ou externos de uma personagem. Talvez o mais correto fosse afirmar que o principal no filme é a cidade, é o dia na cidade, que é composto através das personagens e das suas relações. Em cada uma delas, é a cidade que pulsa, mas a cidade constituída enquanto uma disputa entre o abjeto, a perversão e as demais características relacionadas ao amarelo em geral e a sua esfera correlata, aquilo que Deleuze chama de meio derivado, e que no filme aparece como algo relacionado aos modos de vida.

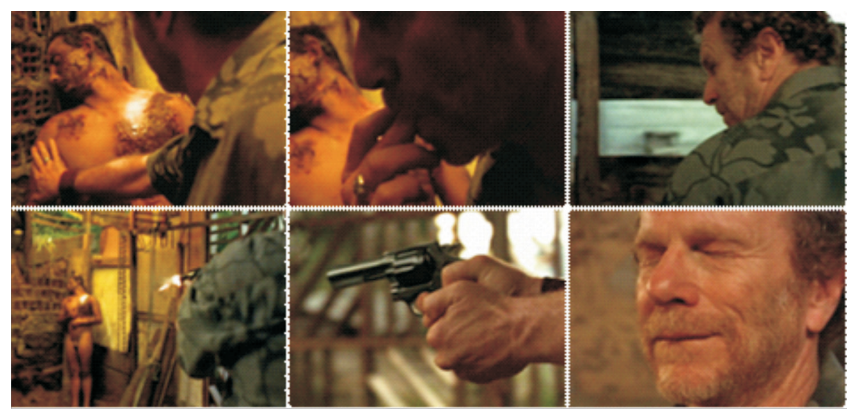

Figura 4 - Caracterização do mundo originário

Fonte: (AMARELO..., 2003) 
No filme existe uma espécie de violência despotencializada que parece ser uma das suas grandes marcas. É uma violência que existe, mas que não tem potência, não afronta diretamente a esfera do civilizado, senão por efeitos adjacentes. O objetivo é compreender que a violência aqui é um impulso, um puro exercício e um puro gozo. O primeiro plano do rosto excitado da personagem, que inclusive encerra a cena, destaca o prazer do ato. Já outro primeiro plano, da arma, traz para a cena um objeto que é comumente associado à potência, ao poder sobre a vida e ao universo da violência urbana no país. O diretor faz questão de enquadrar esse objeto em primeiro plano e assim trazer à cena o universo associado à arma de fogo. Porém, o sentido aqui é subvertido, já que a arma tem um uso impotente, oposto àquilo que ela usualmente encarna. Há, portanto um jogo entre a potência, que é o comum do objeto, e a impotência, que é o uso na cena. A estratégia caracteriza a imagem-pulsão como passagem da afecção (a potência da arma, o prazer na rostidade) à sua não ação. Claramente nestas cenas podemos perceber o caráter entre a afecção e a ação que caracteriza toda imagem-pulsão.

O primeiro plano da arma é o recurso utilizado para inserir na cena o imaginário comum de arma de fogo. Assim, ele cumpre aqui uma função de expressividade, conforme a reivindicação de Eisenstein para esse tipo de plano.

Nesta comparação, a primeira coisa a aparecer claramente diz respeito à principal função do primeiro plano em nosso cinema - destina-se não apenas, e não tanto, a mostrar ou apresentar, mas a significar, a dar significado, a expressar (EISENSTEIN, 2002, p. 207, grifo do autor).

Sabemos que tudo significa no cinema, mas a utilização do primeiro plano é sobretudo potencialidade qualitativa por oferecer destaque a um elemento da cena em geral. Eisenstein, inclusive, prefere chamar de grande plano, ao invés de primeiro plano, porque a terminologia acentua o aspecto de ampliação do objeto na tela, de maneira a reforçar a ideia de atribuir relevância ao objeto. Enfim, é o que ocorre na cena analisada, com relação à arma. Através do primeiro plano, recorre-se ao imaginário da arma, que é ao mesmo tempo questionado por outro uso do objeto que se faz em cena. Configura-se assim um conflito entre potência e impotência, a violência potente e o prazer da violência desprovido de potência.

Ainda na mesma cena, podemos destacar a nítida quebra de luz entre uma fotografia cinza e outra amarela. Sabemos já o que significa o amarelo, através do conceito que o filme explicitamente oferece. E nessa cena o amarelo está no lado do corpo, ocupa a sua porção do espaço. É relevante que é a única vez em que essa tonalidade aparece na fotografia do filme.

A violência aqui permanece no nível do próprio mundo originário, diferente de outras violências que veremos no filme. Há outras violências que existem no nível da tensão entre os dois lados das coordenadas de mundo originário-meio derivado, só que cada uma numa direção. Por um lado, é a pulsão que emerge, por 
outro, é o comportamento que reage. Tais violências estão inseridas num sistema de ação e reação, inclusive imediata e impulsiva, e assim contribuem nos desdobramentos dos fatos da narrativa.

Os frames dispostos abaixo compõem a cena em que a personagem religiosa ortodoxa descobre a traição do marido. Em outra cena, ela havia dito que não perdoaria traição. Depois, após receber uma notícia anônima (para ela, porque o espectador sabe quem a enviou), ela flagra o marido com a amante. No momento em que vê a cena, a personagem enfurece-se e ataca raivosamente a amante, praticando o gesto animalesco de arrancar-lhe um pedaço da orelha. A partir daí, a personagem deixa de modo radical a religiosidade que era sua característica, assumindo a postura "amarelo manga", conforme a nova cor do cabelo que escolhe na última cena do filme.

A exposição da sequência é relevante para observarmos como esse impulso violento está inserido no fluxo narrativo. Há uma progressão de situações que encaminham a ela, bem como uma consequência imediata. Na cena em questão, a violência é a pulsão propriamente dita, o mundo originário que irrompe sobre o meio derivado. Por isso, é uma violência visceral, súbita, e capaz de afetar a personagem num único rompante.

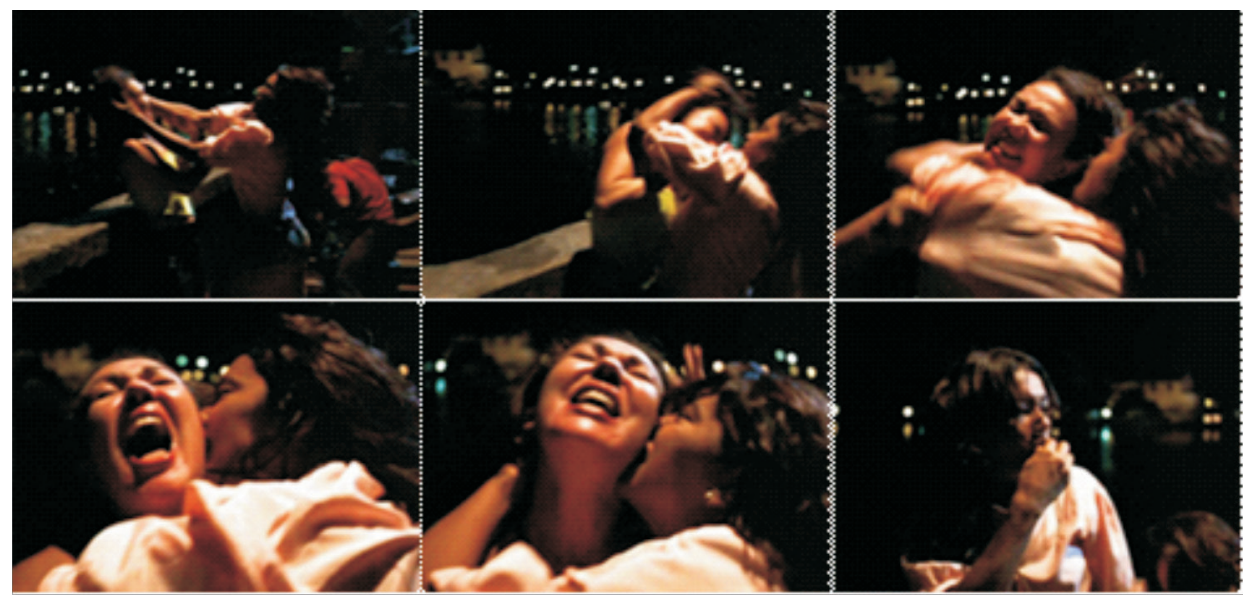

Figura 5 - Pulsão do mundo originário

Fonte: (AMARELO..., 2003)

Em contrapartida, podemos distinguir no filme uma violência que é a reação do meio derivado à pulsão. Essa violência também tem característica reativa. É sempre impulsionada por uma ação fortemente demarcada. A reação é igualmente instantânea, com a diferença, porém, de não ser animalesca, com a da cena anterior. Outra diferença é que essa violência acontece várias vezes ao longo do filme, sempre relacionada à mesma personagem, e não provoca uma consequência súbita, ao estilo de uma grande transformação nas personagens. Resumindo, essa terceira violência do filme é uma reação do meio derivado à pulsão, ocorre várias vezes ao longo do filme, sempre com a mesma personagem e é disparada 
pela repetição, não pela gravidade de um único evento. Eis, novamente, a imagem-pulsão que ao retirar sua qualidade da afecção não chega a se tornar ação, insistindo infinitamente na repetição.

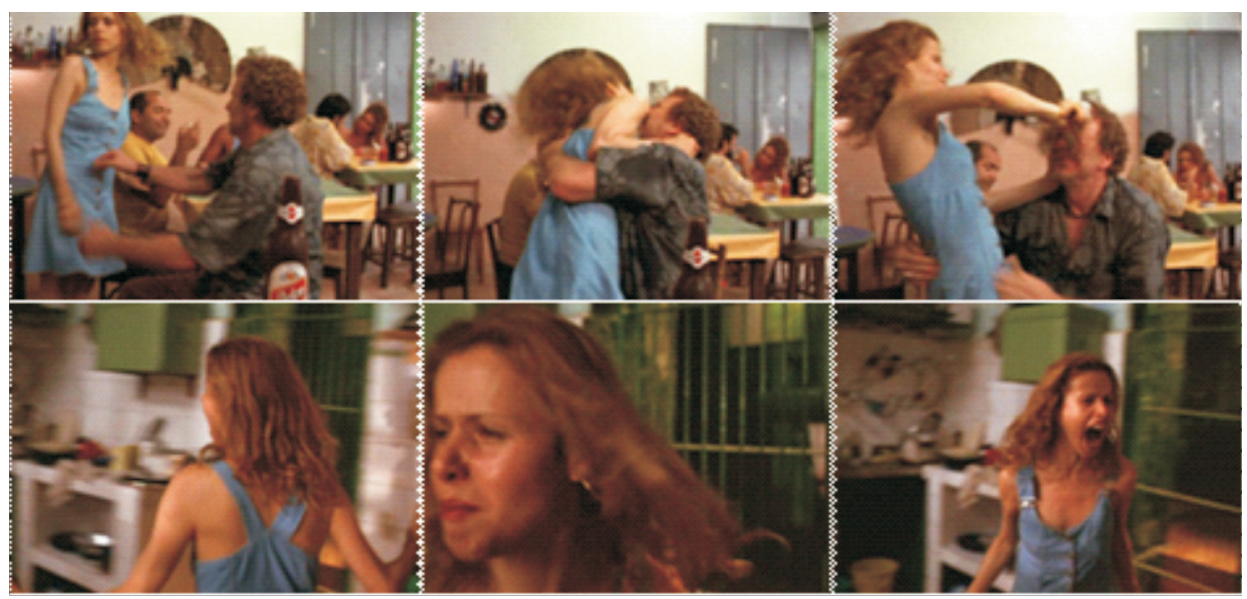

Figura 6 - Reações do meio derivado

Fonte: (AMARELO..., 2003)

Assim, Amarelo Manga explora as tensões ocorridas nas diferentes direções da imagem-pulsão: dos mundos originários aos mundos derivados, e vice-versa. Difere de Cronicamente inviável porque lá a violência é sempre relativa à ação do mundo originário sobre o meio derivado. Em Amarelo Manga, tais passagens multiplicam-se oferecendo uma efetiva classificação das possibilidades de aparição das imagens-pulsão.

\section{Considerações Finais}

$\mathrm{O}$ estatuto das imagens-pulsão em Cronicamente inviável e Amarelo manga teve por objetivo contribuir com o desenvolvimento do conceito de imagem-pulsão proposto por Gilles Deleuze (1985) em Cinema I - a imagem-movimento e verificar de que maneira tal imagem tem sido explorada pelo cinema brasileiro contemporâneo.

Situada entre a imagem-afeção e a imagem-ação, a imagem-pulsão não só foi a menos explorada por Deleuze, como tem sido a menos explorada pelos pesquisadores que procuram pensar o cinema como imagem de pensamento. Por essa razão, neste artigo, procuramos, ao partir da obra de Deleuze, recuar até Freud para melhor caracterizar os sentidos da pulsão na psicanálise e até Marcuse para verificar de que maneira a pulsão foi pensada nas dinâmicas socioculturais para, por fim, reencontrar Deleuze e o nosso desafio: pensar a imagem-pulsão no cinema brasileiro contemporâneo. 
Sua condição de estar entre duas imagens predominantes no cinema das imagens-movimento, e entre a própria imagem-movimento e a imagem-tempo, faz da imagem-pulsão um objeto de investigação instigante e de difícil caracterização empírica. Tal situação conduziu-nos à hipótese de que, contemporaneamente, não há filmes em senso estrito compostos predominantemente por imagens-afecção, mas que elas se insinuam, dispersivamente, em cenas de diferentes filmes.

Apenas sob tal hipótese se tornou possível pensar rigorosamente a imagem-pulsão em filmes como Cronicamente inviável e Amarelo manga. Tal experiência, aqui relatada, oferece também um mapa de passagens. Passagens que em Cronicamente inviável descrevem o modo como o mundo originário cronicamente inviável devém na imagem-movimento ora cínico ora sarcástico, e que, em Amarelo manga, circunscrevem múltiplos movimentos, ativos e reativos, entre os mundos originários esteticamente tematizados pelo amarelo e os mundos derivados das experiências do abjeto, do animalesco, do pútrido.

Este artigo, assim, espera poder contribuir com o debate sobre como tratar a imagem-pulsão na contemporaneidade, que aparece em dispersão em diferentes cenas, para além da clausura do filme.

\section{Notas}

${ }^{1}$ Os conceitos de "imagem-afecção", "imagem-ação" e "imagem-relação" são, respectivamente, equivalentes aos elementos da tríade peirceana "primeiridade", "secundidade" e "terceiridade", e foram utilizados por Deleuze para a composição da taxionomia dos signos cinematográficos realizada em Cinema I: A imagem-movimento (1985/2009).

${ }^{2}$ Por ser uma citação direta, mantém-se aqui o termo instinto, que foi utilizado para traduzir Trieb na publicação de Marcuse. 


\section{REFERÊNCIAS}

AMARELO Manga. Direção: Cláudio Assis. Produção: Cláudio Assis e Paulo Sacramento. São Paulo: Olhos de Cão Produções Cinematográficas, 2002. 1 DVD.

BERGSON, H. A evolução criadora. São Paulo: Martins Fontes, 2005.

BERGSON, H. Matéria e memória. São Paulo: Martins Fontes, 2006.

BURCH, N. Praxis do cinema. Lisboa: Estampa, 1973.

CAMPOS, R. Tempo amarelo: ensaios. Recife: Fundação Nabuco, 1980.

CRONICAMENTE Inviável. Direção: Sérgio Bianchi. Produção: Sérgio Bianchi, Gustavo Steinberg e Alvarina Souza e Silva. São Paulo: Agravo Produções, 2000. 1 DVD.

DELEUZE, G. Cinema 1: a imagem-movimento. São Paulo: Brasiliense, 1985.

DELEUZE, G. Diferença e repetição. São Paulo: Graal, 2006.

DELEUZE, G. Cinema 2: a imagem-tempo. São Paulo: Brasiliense, 2007.

DELEUZE, G. A imagem-movimento. Lisboa: Assírio \& Alvim, 2009.

DELEUZE, G. Los signos del movimento y el tiempo. Buenos Aires: Cactus, 2011.

EISENSTEIN, S. A forma do filme. Rio de Janeiro: J. Zahar, 2002.

FREUD, S. Além do princípio do prazer. Rio de Janeiro: Imago, 1975.

FREUD, S. Formulações sobre os dois princípios do funcionamento mental. In:_. Obras Psicológicas Completas de Sigmund Freud. Rio de Janeiro: Imago, 2009. v. 12. p. 271-286. Edição Standard Brasileira.

FREUD, S. As pulsões e seus destinos. São Paulo: Autêntica, 2013.

LOPES, D. Sensações, afetos e gestos. In: GONÇALVES, O. (Org.). Narrativas sensoriais. Rio de Janeiro: Circuito, 2014. p. 61-82.

MARCUSE, H. Eros e civilização: uma interpretação filosófica do pensamento de Freud. Rio de Janeiro: J. Zahar, 1975. 
STRACHEY, J. Nota do editor inglês. Os instintos e suas vicissitudes. In:

Obras Psicológicas Completas de Sigmund Freud. Rio de Janeiro: Imago, 1974. v. 14. p.129-135. Edição Standard Brasileira.

Recebido em: 02 de julho de 2014 Aceito em: 03 de setembro de 2014 